playing it unbelievably cool, are listening to the latest ball game scores relayed from the Houston space centre, and joking about watching the championships on television.

At about eleven o'clock on Tuesday morning Apollo 8 is due to enter lunar orbit and photograph the lunar surface from a height of only sixty-four miles. The worst hazards will still be ahead. On Christmas Day the spacecraft has to be boosted out of the pull of lunar gravity and on to an Earth bound trajectory, and on Friday afternoon there is the critical re-entry into the Earth's atmosphere. Apart from the inherent problems of hitting the Earth's atmosphere at the correct angle there is now the added problem of frosted. windows, which has been the plague of most of the American astronauts. According to one of the flight directors, "The centre window is very opaque. The other four are somewhat hazy but they are usable for map sitings. The men can see through four of the windows adequately enough to identify the constellations". This reduced visibility should not affect reentry so long as the two mechanical tube displays, which are to give the re-entry attitude, function properly on Friday morning. Like everyone else, we wish Apollo 8 the best of luck for the rest of the mission.

\section{DRUG RESEARCH}

\section{Legality of Cannabis Experiments}

A RECENT experiment on the effect of marihuana in man, conducted at Boston University School of Medicine, has drawn attention to the uncomfortable situation in which research of this sort would be placed in Britain. At a time when the widespread use of the drug, also known as pot, hashish or cannabis resin, makes knowledge of its effect in man all the more necessary, English research workers find themselves inhibited by the Dangerous Drugs Act of 1965 .

Section five of the Act makes it an offence for the owner or occupiers of premises to allow them to be used for the smoking of cannabis. This restriction is absolute, and a scientist undertaking laboratory research on human volunteers would find himself liable to prosecution. The restriction was doubtless reasonable at the time the law was enacted, although had its legislators foreseen the rise of drug taking to its present prominence they would doubtless have worded the Act so as to allow approved research.

As it happens, the Act contains, by accident rather than design, a small loophole. Acts of this nature are held not to apply to the Crown unless specifically stated to do so. It is understood that the Dangerous Drugs Act in fact permits cannabis research on volunteers on government owned premises. Scientists working elsewhere cannot legally do this type of research as the law now stands, and unless government laboratories feel capable of handling all necessary research themselves, it may soon be desirable to effect a change in the law.

The Boston workers, A. T. Weil, N. E. Zinberg and J. M. Nelsen, concluded that it is "feasible and safe to study the effects of marihuana on human volunteers who smoke it in a laboratory" (Science, 162, 1234; 1968). Theirs seems to have been the first study of the drug in man to be undertaken with appropriate control procedures. Protection from legal repercussions was obtained by specific "agreements" with the relevant legal authorities including the Federal Bureau of Narcotics, which was also persuaded to supply the raw material of the experiment. Nonetheless, the authors feel obliged to append to their paper the note that "we do not consider it appropriate to describe here the opposition we encountered from governmental agents and agencies and from university bureaucracies".

Legal impediments were not the only obstacles encountered. On a wry but not irrelevant note, Weil and colleagues mention that it took nearly two months of interviewing to find nine volunteers among the student population of Boston who had never smoked marihuana. The chief results of their study are, in brief, that smoked doses of marihuana have different effects on naive subjects and on habitual users of the drug. In a laboratory setting, at least, non-users did not get "high", even on strong doses, but their performance on simple psychological and psychomotor tests was impaired. Surprisingly the habitual smokers, who did become high, showed no impairment and even a slight improvement on the tests. Marihuana, which appears to be a "relatively mild intoxicant", does not alter the blood sugar levels, which means that the explanation for the well known effects on appetite must be sought elsewhere. There are grounds to suppose that the drug acts on the higher cortical functions without affecting the emotional balance maintained by the lower brain centres.

\section{INFLUENZA \\ Unprotected against Epidemics}

Although the British Government has had more than five months warning of the possibility of an epidemic of Hong Kong flu in Britain this winter, it now looks as though there will be insufficient vaccine to protect more than a small proportion of the population if and when an epidemic does break out. Vaccine production has been left completely in the hands of private firmsBeechams Research Laboratories, Crookes Laboratories and BDH Pharmaceuticals-and it is remarkable, to say the least, that the Microbiological Research Establishment at Porton, with its excellent facilities for growing viruses, has not been approached to ease the load.

The reason for this is not clear, but a good deal of passing the buck seems to be going on. A spokesman at the Department of Health and Social Security said this week that the production of vaccine at Porton is a matter for the Ministry of Defence. It seems, however, that the ministry has not asked for help. In any case, vaccine production is expected to fall 150,000 doses short of the target of 900,000 set for the end of the year, chiefly because of the difficulties in meeting the stringent testing requirements. This suggests that even some of the chronically ill and aged-the two groups entitled to protection-may have to go without vaccine. Admittedly there are repor's of "substantial additional supplies" being imported, but these will have to be carefully tested before use.

Time is certainly not on the Government's side. Until recently it has been working on the optimistic and perhaps convenient assumption that an epidemic is unlikely to hit Britain before mid-February. But with 35 states in America affected, and in view of the present intensity of high-speed travel between America 